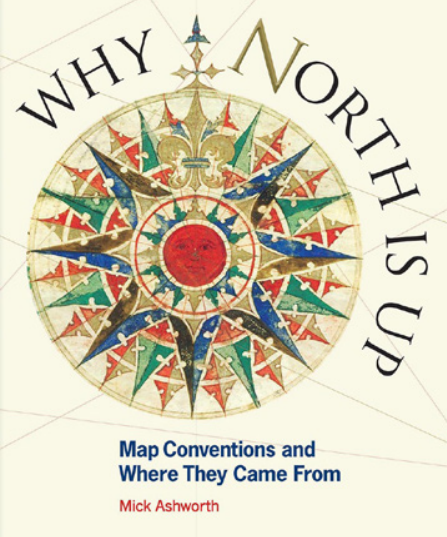

\title{
WHY NORTH IS UP: MAP CONVENTIONS AND WHERE THEY CAME FROM
}

By Mick Ashworth

Bodleian Library/University of Oxford, 2019

224 pages, 109 maps

Hardcover: \$30.00, ISBN 978-1-8512-45192

Review by: Sarah Kelly, University of Colorado Boulder

Why North Is Up: Map Conventions and Where They Came From, by Mick Ashworth is not the dry, textbook-style history of cartographic conventions I expected, but is instead-to my delight - a quite elegant telling of "how widely accepted mapping conventions originated and evolved" (cover blurb), and is beautifully adorned with 109 maps from throughout history.

The book begins with an introduction that provides background information on the various types of maps found throughout the volume, and the many difficulties faced by cartographers in making quality maps-difficulties such as determining an appropriate scale, representing a spherical planet on a flat piece of paper, and selecting map symbols. Ashworth explains how each of these choices can lead to map features being misrepresented, and why readers should exercise caution when interpreting maps. The introduction concludes with a note explaining that (unspecified) emerging conventions are changing the way we interpret and interact with maps.

The book is divided into seven Parts: "Map Structure," "Symbols," "Representations of Relief," "Names and Boundaries," "Thematic Maps," "Specialized Conventions," and "Post-Convention Mapping." Each Part contains between two and seven short, easily digestible chapters. At the end of the book are "Notes and Further Readings," credits for all the maps, and a handy index.

The book takes its title from the topic of the first chapter of Part I: "Map Structure," which discusses why most maps today are oriented with north at the top. Clearly, "the Earth doesn't have a top and a bottom" (7), and there is no rule that explicitly states that north must be at the top of the map, so how is it this practice has become uniform? Ashworth focuses on the factors that may have influenced the adoption of this convention, and his discussion is supported with many south-up map examples. These range from al-Idrīsis's world map from the sixteenth century to McArthur's Universal Corrective Map of the World from 1979. The chapter concludes with mention of technological advances, such as Google Maps, which, when zooming out, offers users a globe that they can spin to whatever orientation they please, helping make the "north up" convention less imperative in daily map use.

The second chapter is dedicated to latitude and longitudehow, and by whom, such lines were defined, when we first saw such systems used, and what it was that spurred the development and use of prime meridians. Early maps, such as the "map of the world published by Donnus Nicolaus Germanus, circa 1460, based on Ptolemy's Geographia, circa 150 CE" (14) compliment the text (Ptolemy had been the first to use the terms latitude and longitude when describing grid coordinates). In the third chapter the author deals with map projections, beginning with the classic orange peel example, demonstrating the impossible task of transforming a spherical surface to a flat one without disruptions and distortions. Important concepts such as projection families, map scale along the line of tangency, rhumb lines, and projections that preserve metric properties (such as equidistance) are touched upon, but there is 
a lot left out or glossed over. For example, insufficient information is provided about the main properties of map distortion (shape, area, distance, direction) to allow them to be understood in any meaningful way, and the chapter lacks any mention of projection aspect or geodesy, although, admittedly, geodesy may well be beyond the scope of this popular-level book.

The fourth chapter in Part I opens with a grim example of how grids were used in World War I to record body counts, but it then goes on into the wider history of grid use. Early examples include a Chinese map dating from the twelfth century (Yu ju tu, circa 1137) and John Norden's Myddlesex (1593), the first map to use an alphanumeric grid index system much like the ones we often see in present-day atlases. More recent developments such as the British National Grid (BNG) and the Universal Transverse Mercator (UTM) systems are also discussed, along with an explanation of the concept of eastings and northings used by these and similar systems.

Scale, an important concept often overlooked by amateur cartographers, is presented next. Ashworth accurately states that "with reduced map scale come limitations both on what it is possible to show and how it can be represented" (35). In addition, he describes the three methods for representing scale-graphical (scale bars), mathematical (representative fractions), and descriptive (this to every that; for example, one inch to every mile). Map examples include some with very ornate graphical scale representations from the sixteenth and seventeenth centuries and a beautiful topographic map of Mont Blanc from 1865 that uses all three methods to represent scale.

The last two chapters of Part I, "Legends: What does it all mean?" and "Ornament: Art meets science," together speak to the features of a map that support its usability and lend it an air of authority-by providing a key to the map symbols used and by stylistically signaling to the reader the professionalism of the maker. In earlier times, for example, map legends were presented in very ornate cartouches or decorative panels-Christopher Saxton's Norfolciae (1579) is the example shown-but since that time mapmakers have more and more tended to "adopt the much simpler, functional styles with which we are familiar today" (53) - as is seen in the Former Yugoslavia Series $M 709$ 1:50,000 Sheet Vareš (U.S. Defense Mapping Agency 1995). Along with ornate legends, early maps often had elaborate borders and map symbols that, to modern eyes, at least, made these maps look more like works of art than scientific documents. This effect is shown with some magnificent examples, such as Willem Janszoon Blaeu's Nova totius terrarum orbis (circa 1606).

Part II of the book has six chapters dedicated to map symbols and their use. The first chapter focuses on the symbols themselves in their three basic forms-points, lines, and areas - and their basic styles-pictographic and geometric. The concept of visual variables such as shape, size, and

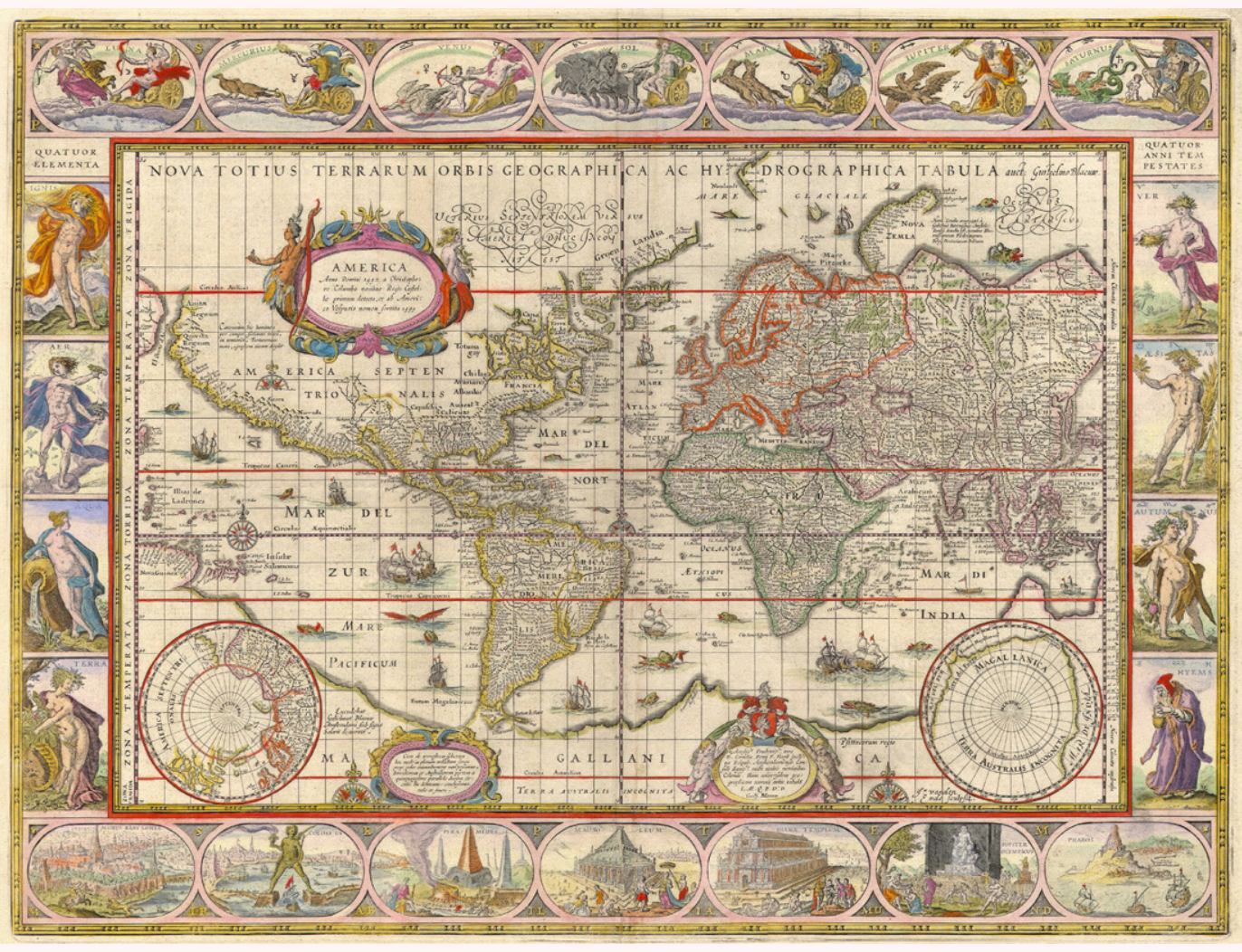

Nova totius terrarum orbis, Willem Janszoon Blaeu. 
hue is introduced, with examples of how they are used. The variables of orientation and position in the plane are not included, presumably because they are less commonly used.

Each of the next three chapters are devoted, in turn, to the various ways each of the basic symbol forms can be employed-starting with points. Point features can be represented by either geometric shapes or pictographic symbols. Ashworth, however, proposes that while geometric symbols are generally easier to find, the use of pictographic symbols allows for faster interpretation. I would disagree with him on this. It is true that pictographs can carry more connotative detail-perhaps aiding feature interpretation-but this individuality is usually at the expense of a larger symbol size. Large point symbols can quickly clutter the map, often making interpretation of the map (as opposed to the feature) more difficult. Similarly, Ashworth also feels that the variable of shape, along with that of size, is appropriate for indicating a hierarchy among point features. This view, however, contradicts the orthodox convention that dictates that while shape can be used effectively for grouping features of different types, it cannot be used to establish hierarchy.

The next chapter, "Line Symbols: Keeping on track," focuses on transportation networks, with examples such as Harry Beck's London Underground (1933). Only one line symbol map produced prior to the nineteenth century is included-an extract from the Book on Navigation by Piri Reis (1525) - and I was surprised that W. R. Gardner's 1823 Comparative Heights of the Principal Mountains And Lengths of the Principal Rivers in The World was not, although John Ogilby's Road from London to Aberistwith (1665) is referenced in a sidebar. The text mentions, and provides examples of the use of, different textures and hues to represent different types of line features, and of widths for indicating quantitative differences.

Ashworth then moves to area symbol representation, where he emphasizes their importance in a discussion of the Map of Eastern Turkey in Asia, Syria and Western Persia (Royal Geographical Society, 1916), which identified how the British and French intended to divide the Middle East between them once World War I concluded. Many maps representing area features include political divisions, but they often also show natural features such as ecosystem classifications, or statistical information such as COVID19 cases by country. Area color was a problem for early maps - often having to be applied by hand-but the introduction of lithographic printing in the nineteenth century made printing areas of nuanced color variation much simpler and cheaper. This discussion of color segues into the next chapter- "Colour: Deep blue sea?"-which briefly discusses how color use has evolved, the emotive connotations implied by color, and the role our "understanding of light, electromagnetic radiation and optics" (88) has played in evolving mapping practice. The author points out that current color conventions were well established by the mid-nineteenth century, and he speculates that the advent of online mapping may lead to the development of further styles and conventions.

The final chapter in Part II is on generalization, an important topic that is often overlooked by both map readers and makers. It starts by discussing the importance of scale and map purpose relative to generalization and then moves into generalization techniques, though no comprehensive list of these techniques is provided. The author stresses that in generalization there are no rules or conventions that apply across the board. He chooses to illustrate the potential for generalization techniques to be used in the manufacture of propaganda with England's Raids over 5 Continents 1605-1940, a 1941 map by Alois Moser, although many better examples of propagandizing generalization exist.

Part III is all about the "Representation of Relief," with five chapters that explore the various ways that elevation can be portrayed. Spot heights and soundings come first, and the author is careful to point out the difficulties encountered in trying to represent, or read, the overall character of terrain with discrete measurements alone. The next technique is hachures-lines that run downslope in order to portray relief and slope. First used in the seventeenth century, hachures are no longer commonly employed, although Ashworth writes that "there is still room in cartography for the[se] more subjective and artistic methods" (109). This chapter includes some beautiful examples of both landscape and nautical maps employing hachured terrain. A chapter on "Contours and Isobaths: On the level" follows, and provides background on when, where, why, and by whom contour lines were first used. The various types of contours are explained, and early map examples are presented.

The next chapter in Part III is about the use of "layer colors" to depict elevations and depths-also known as 
hypsometric or bathymetric tints, respectively. The early history of their use is explained, but the most interesting aspect covered is that of the debates surrounding the sometimes very different color gradation schemes that have been used for representing relief. A rundown of the various confusions that can arise when using color to portray landscape elevations, along with the potential complications that can occur when these colors are used in conjunction with other relief portrayal techniques, closes out the chapter. The final chapter in Part III, "Hill Shading: Out of the shadows," examines this mimetic technique that strives to give the perception of a three-dimensional landscape through the use of idealized shadowing cast by a hypothetical light source illuminating the terrain from an oblique angle. The sample maps the author included to accompany this chapter bear out his remark about "the best examples [of hill shading] being the perfect blend of art and science in map-making" (127).

Part IV, "Names and Boundaries," has three chapters, with the first being "Place Names: Putting a name to it." The chapter begins by providing a place name-in this case, Paris, France - along with its geographic coordinates, and then proceeds to demonstrate that there are multiple ways in which we can name what is at that location. Ashworth is quick to point out that place names on maps can be quite subjective, and can vary by language and by political agenda. The conventions pertaining to the placement of text associated with map features are discussed briefly as well. The second chapter, "Boundaries: Drawing the line," discusses how line texture and color can be used to represent different types of boundaries, and includes a look at the significantly different ways lines representing boundary features can be drawn, depending on, among other things, a mapmaker's viewpoint or the geopolitical standing of the area being depicted. The third and final chapter is entitled "Typography: Keep it clear," and it deals with the various styles and forms that text on a map can take. Ashworth focuses on the main principles of typography—text positioning, font style, size, weight, and relative hierarchy. One of the example maps presented is a T-O map from 1472, but no modern maps are included.

Part V, “Thematic Maps," has only two chapters, "Qualitative Thematic Maps: What do we have here?" and "Quantitative Thematic Maps: How many are there?" In the first chapter, Ashworth discusses the difference between general (reference) and thematic maps, and discusses the common pitfalls encountered by makers of thematic maps (for example, using overly complicated pictorial symbols and/or mapping too many phenomena). Unfortunately, this chapter (along with the next one) proved to be the biggest disappointment of Why North Is $U_{p}$, as the reader is misinformed on a few topics. One example regards the first graphic presented in this chapter: John Snow's famous Map of Soho, London, showing cholera deaths in 1855. Ashworth claims that this map is qualitative, ignoring the fact that it uses small black bars to show the count of individual deaths occurring at each address. Counts are quantitative in nature and, even if no mortality numbers are written directly on the map and no comparative statistics with deaths in adjoining areas are given, the map is still representing numerical information and should therefore be included in the chapter on quantitative maps.

The quantitative chapter goes into some detail on methods for mapping numerical thematic information, such as choropleth maps and graduated symbol maps. Cartograms, too, are discussed briefly in a sidebar, but no examples of such maps are included. Unfortunately, the author inappropriately conflates proportional symbols with graduated symbols, and furthermore, he incorrectly states that the visual variables of shape and orientation can be used to represent differences in relative value. Unreliable information of this sort seriously undermines the real value the rest of this book delivers.

Part VI is about "Specialized Conventions," and includes chapters on geologic maps, hydrographic charts, military maps, and global mapping (in particular, Albrecht Penck's vision for the International Map of the World in 1891 and the difficulties that the venture encountered), with some beautiful examples accompanying each topic. While each of these topics have come up previously, these chapters go into more detail and elaborate on the history of each.

The final part of the book, Part VII, "Post-Convention Mapping," has three chapters on some of the more recent advances in cartography. The first chapter, "Different Perspectives: Picture this," is all about maps that portray features with a "bird's-eye view." The exquisite examples include Heinrich Berann's Yellowstone National Park (1991), along with some other, older, examples. The development of aerial photography, satellite imagery, and light detection and ranging (lidar) are mentioned as well. The second chapter focuses on the development of digital mapping technologies such as GPS and GIS, along with online mapping systems, and how such technology requires 
mapmakers to consider cartographic conventions in relation to digital map functionality (for example: dropping pins, URL links to other data sources, route tracking), but does not make any mention of the concerns around locational privacy. The final chapter covers what the author terms the democratization of cartography-crowdsourcing, open source data, and how we are all contributing to digital maps even if we are not aware of it.

The book ends abruptly, with no closing remarks, but it does provide a succinct list of resources for further reading.

Overall, I believe Ashworth has met his goal of providing a background on the origins and role of mapping conventions, and he does so with interesting stories, beautiful maps, and a comprehensive list of topics presented in succinct chapters. I have pointed out a few issues I found with some of the information he presented such as those related to map symbols and thematic mapping. I also found that not all of the many maps included in the book are referenced in the text, and that there are other maps that are mentioned without reference to a page or figure number. Despite these shortcomings, I am not at all deterred from recommending Why North Is Up: Map Conventions and Where They Came From to both novice and experienced mapmakers. It provides the reader with the very interesting history of map conventions, accompanied with many gorgeous illustrations that are not typically presented in cartography textbooks. This book can serve as a reference for cartographic scholars while also being an enjoyable read for anyone interested in the history of maps and mapmaking. 